\title{
A influência dos gases estufa no oceano Atlântico Sul: Estudo climatológico
}

\author{
(The effect of greenhouse gases on South Atlantic Occan: A climatological study)
}

\author{
Andréa S. Taschetto \& Ilana Wainer \\ Instituto Oceanográfico da Universidade de São Paulo \\ (Praça do Oceanográfico, 191, 05508-900 - São Paulo, SP, Brasil)
}

- Abstract: The purpose of this study is to analyze the impact of the increase in greenhouse gases caused by the industrialization in the climate of the South Atlantic Ocean. We used the National Center for Atmospheric Research - Community Climate System Model. Two climate conditions were used to force the model, one relative to the pre-industrial levels of greenhouse gases emissions and the other to the levels of the present days. The results have shown a significant sea surface warming in pos-industrial climatology in relation to the pre-industrial one, mainly during the spring season when it reaches $2.5^{\circ} \mathrm{C}$ south of South America. The climatological behavior of the barotropic streamfunction and the sea level pressure also showed relevant differences from one period to the next. This suggests an intensification of the subtropical high, the subtropical gyre and the Antaretic Circumpolar Current. Seasonally, the differences in the barotropic streamfunction were larger in autumn with values as high as $25 \mathrm{~Sv}$ around $0^{\circ} \mathrm{E}, 55^{\circ} \mathrm{S}$. The sea level pressure for present simulation shows a strenghtening in summer and autumn with an intensification of $2 \mathrm{mbar}$, and a weakening in winter in relation to the pre-industrial period.

- Resumo: O presente trabalho tem como objetivo analisar os impactos climáticos no oceano Atlântico Sul causados pela industrialização e consequiente aumento da emissão de gases estufa para a atmosfera. Para isso utilizou-se o modelo numérico acoplado National Center for Atmospheric Research - Community Climate System Model, sob duas condições climáticas: a primeira para o periodo pré-industrial e, a segunda, para o pós-industrial. Os resultados mostraram aquecimento da superfície do mar na climatologia do período pós-industrial em relação ao préindustrial, principalmente durante a primavera quando alcança $2,5^{\circ} \mathrm{C}$ ao sul do continente sulamericano. O comportamento climatológico do transporte barotrópico e da pressão ao nível do mar também mostraram diferenças significativas de um período para o outro, sugerindo a intensificação da Alta Subtropical, Giro Subtropical c Corrente Circumpolar Antártica. Sazonalmente, as diferenças no transporte barotrópico foram maiores no outono, exibindo valores superiores a $25 \mathrm{~Sv}$, em torno de $0^{\circ} \mathrm{E}, 55^{\circ} \mathrm{S}$. A pressão atmosférica ao nível do mar foi levemente fortalecida no verão e outono, com intensificação máxima de $2 \mathrm{mbar}$, e enfraquecida no inverno do período pré-industrial para a simulação do presente.

- Descriptors: Climatic changes, Global warming, South Atlantic.

- Descritores: Mudanças climáticas, Aquecimento global, Atlântico Sul. 


\section{Introdução}

Mudanças climáticas podem afetar a biodiversidade dos ecossistemas, bem como a pesca e a produtividade agrícola. Há evidências de que o clima vem sendo alterado pela ação humana desde a época da Revolução Industrial, no final do século XIX, devido à enorme emissão de gases estufa na atmosfera (Houghton et al., 1992; Mitchell, 1989).

O vapor d'água, presente na atmosfera terrestre em altas concentrações, é responsável por $80 \%$ do efeito estufa natural, enquanto que os outros $20 \%$ são devidos aos gases traços presentes na atmostera que, apesar de suas pequenas concentrações, contribuem significantemente para o efeito estufa. Liderando os gases estufa está o dióxido de carbono $\left(\mathrm{CO}_{2}\right)$. mas existem outros gases importantes como o metano $\left(\mathrm{CH}_{4}\right)$, os clorofluorcarbonos $\left(\mathrm{CFC}_{11}\right)$ e $\left(\mathrm{CFC}_{12}\right)$, óxido nitroso $\left(\mathrm{N}_{2} \mathrm{O}\right)$, e ozônio $\left(\mathrm{O}_{3}\right)$, conforme mostra a Tabela $\mathrm{I}$.

$\mathrm{O}$ aumento da concentração do $\mathrm{CO}_{2}$ de 280 ppmv para 355 ppmv durante os últimos 100 anos se deu de forma quase que exponencial devido primeiramente ao crescimento da queima de combustiveis fósseis conforme mostra Solomon el al. (1985). Esse aumento significativo no $\mathrm{CO}_{2}$ atmosférico não é observado em outras épocas, segundo registros de testemunhos de gelo (Ioughton
\& Woodell, 1989) e por isso acredita-se que a ação antrópica seja a principal responsável por essa mudança.

Numerosos estudos têm sido publicados sobre a variação da temperatura média anual (Cane et al., 1997; Houghton et al., 1995) e, embora eles tenham diferenças em alguns detalhes, todos mostram uma característica comum: o crescimento da temperatura média do ar durante o último século, totalizando aproximadamente $0,5^{\circ} \mathrm{C}$ (Skimer \& Porter, 1995). Acredita-se que o aumento da concentração de $\mathrm{CO}_{2}$ atmosférico tenha influência direta no aumento de temperatura do último século.

Uma das projeções futuras simuladas por modelos numéricos é o aquecimento da superfície do planeta (Iloughton el ctl., 1995 e Gates, 1993). Levitus et al. (2000) quantificaram um aumento na temperatura média do oceano global de $0,06^{\circ} \mathrm{C}$, entre as décadas de 50 e 90 , correspondendo a uma taxa de $0,3 \mathrm{~W} / \mathrm{m}^{2}$, desde a superfície até $3000 \mathrm{~m}$ de profundidade. Crowley (2000) concluiu que aproximadamente metade das variações de temperatura de escala decadal pré-antropogênicas (antes de 1850) foram devido a mudanças na irradiância solar e vulcanismo. O autor sugeriu que a variabilidade natural tem um papel secundário no aquecimento do século 20 e que a explicação para a maioria do aquecimento desse período é o aumento antropogênico dos gases estufa.

Tabela 1. Principais gases traços atmosféricos responsáveis pelo efeito estufa. Adaptado de Skinner \& Porter (1995).

\begin{tabular}{|c|c|c|c|c|c|c|}
\hline & $\mathrm{CO}_{2}$ & $\mathrm{CH}_{4}$ & $\mathrm{CFC}_{11}$ & $\mathrm{CFC}_{12}$ & $\mathrm{~N}_{2} \mathrm{O}$ & $\mathrm{O}_{3}$ \\
\hline Efeito estufa & aquecimento & aquecimento & aquecimento & aquecimento & aquecimento & $\begin{array}{l}\text { aquecimento (ar) e } \\
\text { resfriamento (nuvens) }\end{array}$ \\
\hline $\begin{array}{l}\text { Principais fontes } \\
\text { antropogênicas }\end{array}$ & $\begin{array}{l}\text { combustiveis } \\
\text { fósseis e } \\
\text { deflorestação }\end{array}$ & $\begin{array}{l}\text { cultura de arroz; } \\
\text { criação de gado; } \\
\text { combustiveis } \\
\text { fósseis e queima } \\
\text { da biomassa }\end{array}$ & fertilizantes & $\begin{array}{l}\text { geladeiras: } \\
\text { acrossóis: } \\
\text { processos } \\
\text { industriais }\end{array}$ & $\begin{array}{c}\text { hidrocarbonetos: } \\
\text { queima de biomassa }\end{array}$ & irrigaçào \\
\hline $\begin{array}{c}\text { Principais fontes } \\
\text { naturais }\end{array}$ & $\begin{array}{l}\text { balanceado na } \\
\text { nature\%a }\end{array}$ & mangues & $\begin{array}{l}\text { solos. } \\
\text { florestas } \\
\text { tropicais }\end{array}$ & nenhuma & hidrocarbonetos & evapotranspiração \\
\hline $\begin{array}{c}\text { Tempo de vida na } \\
\text { atmosfera }\end{array}$ & 50 a 200 anos & 10 anos & 150 anos & 60 a 100 anos & semanas a meses & dias \\
\hline $\begin{array}{c}\text { Concentração na } \\
\text { atmosfera no } \\
\text { presente (ppbv) }\end{array}$ & 355.000 & 1720 & 310 & $\begin{array}{l}\mathrm{Cl}^{2} \mathrm{C}_{11}: 0.28 \\
\mathrm{CF}^{2} \mathrm{C}_{12}: 0.48\end{array}$ & 20 a 40 & 3000 a 6000 \\
\hline $\begin{array}{l}\text { Concentração na } \\
\text { atmosfera no } \\
\text { período pré- } \\
\text { industrial (ppbv) }\end{array}$ & 280.000 & 790 & 288 & 0 & 10 & desconhecido \\
\hline $\begin{array}{l}\text { Taxa de aumento } \\
\text { anual no presente }\end{array}$ & $0.5 \%$ & $1.1 \%$ & $0.3 \%$ & $5 \%$ & 0.5 a $2.0 \%$ & desconhecido \\
\hline $\begin{array}{l}\text { Contribuição ao } \\
\text { efeito estufa } \\
\text { antropogênico }\end{array}$ & $60 \%$ & $15 \%$ & $5 \%$ & $12 \%$ & $8 \%$ & desconhecido \\
\hline
\end{tabular}


Além do aquecimento da superficie, existem vários estudos que mostram outras conseqüências devido ao aumento na concentração de $\mathrm{CO}_{2}$, tais como: o enfraquecimento da circulação termohalina (Manabe \& Stouffer, 1994); a redução do gelo do mar (Robin, 1986) e o aumento no nível médio do mar (Wigler \& Raper. 1987). Matear \& Hirst (1999) acreditam que com o aumento do $\mathrm{CO}_{2}$ ocorra a reorganização do ciclo do carbono marinho. Outros trabalhos abordam impactos na temperatura do planeta como: o resfriamento da estratosfera (Angell, 1986); o aumento da temperatura noturna principalmente sobre os continentes (Karl et al., 1991); o aumento da temperatura nas regiões polares, principalmente durante o inverno (Gates, 1993); e, verões mais quentes a sccos nas regiões continentais em latitudes médias (Manabe et al., 1981). Bradley et al. (1987) acredita que os padrões de precipitação sejam alterados devido ao aquecimento causado pelo aumento dos gases estufa. McCabe et al. (2001) verificaram o aumento na freqüência dos ciclones de alta latitude e intensificação das tempestades nas médias latitudes associados com o aumento da temperatura do ar.

Este estudo visa analisar os impactos no Atlântico Sul causados pelo aumento da concentração de gases estufa na atmosfera, através de um modelo acoplado de circulação geral. O capítulo seguinte descreve as componentes do modelo c as condições usadas nas simulações. As diferenças climatológicas dos parâmetros de temperatura da superfície do mar, pressão atmosférica ao nivel do mar e transporte barotrópico entre os dois experimentos são apresentadas no capítulo 3 .

\section{Materiais e métodos}

Para se estudar as possíveis mudanças climáticas causadas pelo aumento dos gases estufa, utilizou-se o modelo numérico acoplado National Center for Atmospheric Research - Community Climate System Model (NCAR CCSM) para simular dois experimentos: um para o período pré-industrial c outro para o pós-industrial. Ambos experimentos foram gerados continuamente por um período de 150 anos.

\section{Os experimentos numéricos}

O experimento pré-industrial representa a simulação das condições atmosféricas encontradas para o ano de 1800 aproximadamente. As concentrações dos gases traços, estimadas dos registros de testemunhos de gelo (Ice Core Working Group, 1998; Fluckiger et al., 1999; Indermuhle et al., 1999), foram fixadas em 280ppmv para o $\mathrm{CO}_{2}$, 700 ppbv para o $\mathrm{CH}_{4}, 275$ ppbr para o $\mathrm{N}_{2} \mathrm{O}$, e zero de clorofluorcarbonos. A constante solar foi fixada em $1365 \mathrm{Wm}^{-2}$

O cxperimento pós-industrial difere do anterior basicamente pelas quantidades de gases traços. Esse experimento representa a simulação para as condições atuais (em torno de 1990) com as seguintes concentrações de gases: 354,40 ppmv para o $\mathrm{CO}_{2}, 1722,30 \mathrm{ppbv}$ para o $\mathrm{CH}_{4}, 308,40$ ppov para o $\mathrm{N}_{2} \mathrm{O}$. 0,51 ppbv para o $\mathrm{CFC}_{11}$ e 0,46 ppov para 0 $\mathrm{CFC}_{12}$. A constante solar foi fixada em $1367 \mathrm{~W} / \mathrm{m}^{2}$.

\section{O modelo numérico}

O NCAR CCSM é um modelo numérico acoplado de circulação global oceano-atmosfera, composto por 4 componentes: atmosférica, oceânica, da biosfera e hidrosfera, e da criosfera (Boville \& Gent, 1998).

A componente atmosférica é a versão 3 do modelo atmosférico de circulação geral Community Climate Model (CCM3), com resolução espectral de T42, isto é, aproximadamente $2,8^{\circ}$ na latitude e longitude, e 18 níveis verticais, sendo a camada superior em 2,9hPa.

O CCM3 é a quarta geração nas séries do NCAR CCM. Muitos aspectos da formulação e implementação do modelo são idênticas à versão anterior (CCM2), contudo importantes mudanças foram incorporadas nas parametrizações físicas dos processos climáticos, tais como a inclusão no formalismo de radiação de céu claro dos gases traços $\mathrm{CH}_{4}, \mathrm{~N}_{2} \mathrm{O}, \mathrm{CFC}_{11}$ e $\mathrm{CFC}_{12}$. Além desses gases, tnmbém foram inclusas as propriedades radiativas de duas bandas de $\mathrm{CO}_{2}$, localizadas em $9,4 \mu \mathrm{m}$ e $10,4 \mu \mathrm{m}$, na parametrização de onda longa, e a incorporação de um aerossol de fundo na parametrização de onda curta.

O CCM3 incorpora a versão 1 do modelo de superfícic terrestre Land Surface Model (LSM) desenvolvido por Bonan (1996), que proporciona o amplo tratamento dos processos de superfície de terra. $\dot{E}$ um modelo unidimensional de trocas de energia, momentum, água e de $\mathrm{CO}_{2}$ entre a atmosfera e o solo. O LSM considera as diferenças ecológicas das vegetações, as diferenças térmicas e de umidade dos solos, levando em conta vários tipos de superfície (como lagos e mangues) dentro de uma mesma célula de grade.

O modelo de circulação oceânica é o NCAR Climate System Ocean Model (NCOM), desenvolvido no Geophysical Fluid Dynamics Laboratory (GFDL), a partir do Modular Ocean Model (MOM). Esse modelo é constituido de equações primitivas do momentum, hidrostática e continuidade, resolvidas em coordenadas esféricas, que são formuladas usando um esquema de diferenças finitas de segunda ordem na grade B de Arakawa, conservando massa e energia na ausência de dissipação por forçamentos explícitos. A 
configuração do NCOM apresenta $2,4^{\circ}$ de resolução na longitude e resolução variável da latitude, sendo o espaçamento mínimo da grade de $1,2^{\circ}$ próximo ao equador e pólos (acima de $60^{\circ}$ ), e máximo de $2,3^{\circ}$ nas latitudes médias (em $20^{\circ} \mathrm{N}$ e $20^{\circ} \mathrm{S}$ ). $\mathrm{Na}$ vertical, a componente oceânica possui 45 níveis, com espessura variável aumentando monotonicamente de $12,5 \mathrm{~m}$ a $250 \mathrm{~m}$. Existem 4 níveis de profundidade nos primeiros $50 \mathrm{~m}$, com espessuras iguais de $12,5 \mathrm{~m}$. A profundidade máxima do oceano é de $6 \mathrm{~km}$. Detalhes do NCOM são descritos em Gent et al. (1998).

Acoplado ao modelo oceânico está um modelo de gelo do mar Climate Sea-Ice Model (CSIM), calculado na mesma grade. Essa componente inclui dinâmica e termodinâmica de gelo, baseada no modelo de três camadas de Semtner (1976).

As componentes do modelo são ligadas através de um programa denominado Flux Coupler. Esse acoplador é responsável pela integração das componentes e pela interpolação entre as diferentes grades das componentes do modelo enquanto conserva as propriedades locais e globais, não necessitando, portanto, de correções nos fluxos de momentum, calor e água doce.

\section{Metodologia}

A região foi caracterizada através das climatologias anual e sazonal de ambos experimentos. A climatologia sazonal foi calculada através da média dos meses referentes a cada estação do ano. Assim, para o Hemisfério Sul, a climatologia de verão contou com os meses de dezembro, janeiro e fevereiro (DJF); a climatologia de outono, com março, abril e maio (MAM); a de inverno, a partir de junho, julho e agosto (JJA); e, a de primavera, com setembro, outubro e novembro (SON). A climatologia anual foi calculada através da média de todos os meses.

Com o intuito de apresentar uma estimativa de erros para os resultados da climatologia anual, calculou-se a variância de cada variável para ambos experimentos.

As diferenças entre os períodos pré e pósindustrial foram calculadas. As variáveis usadas nesse estudo foram: temperatura da superficie do mar, pressão atmosférica ao nível do mar e função de corrente do transporte barotrópico.

A seguir serão apresentadas as climatologias da simulação para o período pré-industrial e posteriormente as diferenças entre as simulações dos dois períodos.

\section{Resultados}

Climatologias anual e sazonal do período préindustrial

Tenperatura da Superficie do Mar (TSM)

A climatologia anual da TSM na região de estudo é mostrada na Figura la. O Atlântico Sul é caracterizado por gradientes meridionais de temperatura que tornam-se maiores ao sul de aproximadamente $35^{\circ} \mathrm{S}$ e menores ao norte dessa latitude onde a bacia é mais quente. A TSM diminui em direção ao pólo sul devido à contribuição da radiação solar média anual na superfície do planeta. Esse padrão característico da TSM é concordante com o comportamento médio anual proveniente dos dados observacionais do COADS - Comprehensive OceanAtmosphere Data Set (da Silva et al., 1994) e de Reynolds \& Smith (1994).

A Figura lb apresenta a variância associada à climatologia anual do período pré-industrial. A variância é mais baixa na região tropical, acima de $10^{\circ} \mathrm{S}$ aproximadamente, e maior na costa sudeste e sul da América do Sul. Em torno de $40^{\circ} \mathrm{S}, 55^{\circ} \mathrm{S}$, a variância é máxima com $22^{\circ} \mathrm{C}^{2}$, caracterizando a alta variabilidade sobre a região da Confluência BrasilMalvinas.
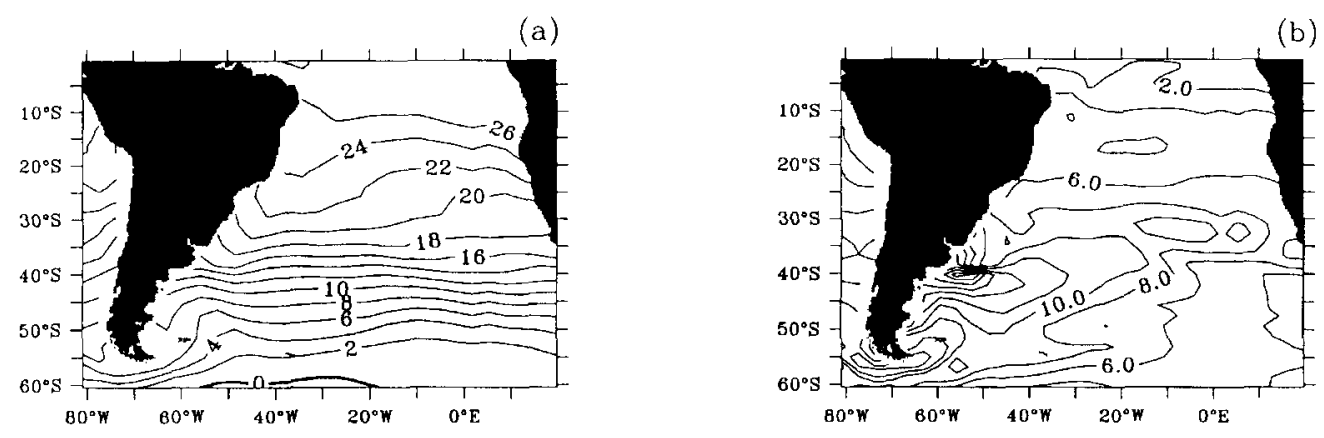

Fig. 1. (a) Climatologia anual da TSM para o período pré-industrial. Intervalos de contornos de $2^{\circ} \mathrm{C}$. (b) Varianncia da TSM para o periodo pré-industrial. Intervalos de contornos de $2^{\circ} \mathrm{C}^{2}$. 
(a)

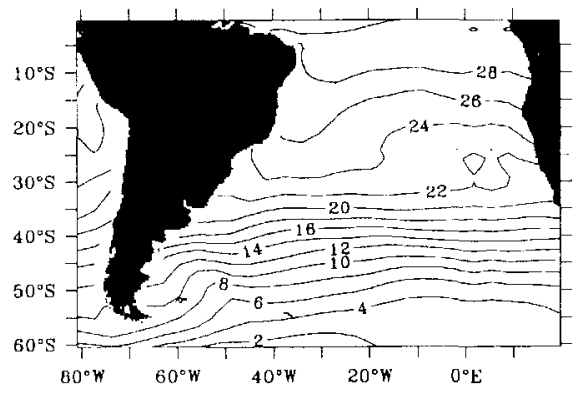

(c)

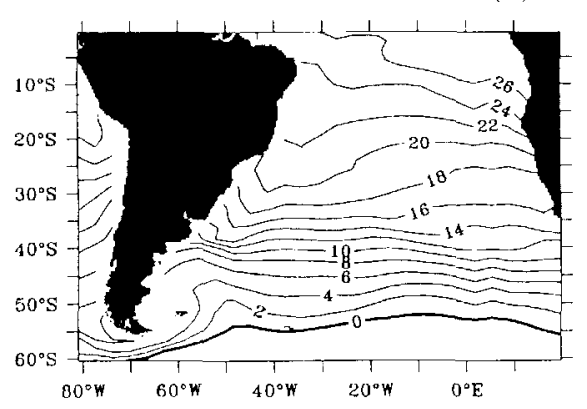

(b)

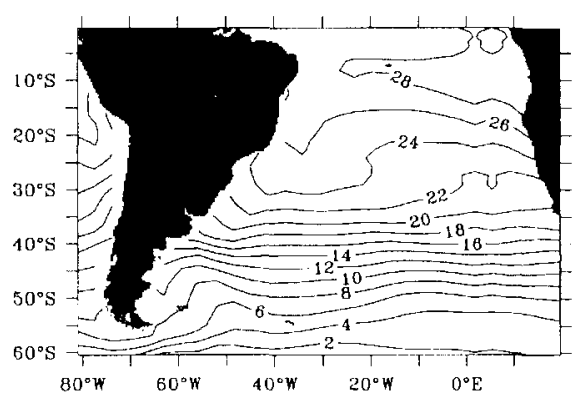

(d)

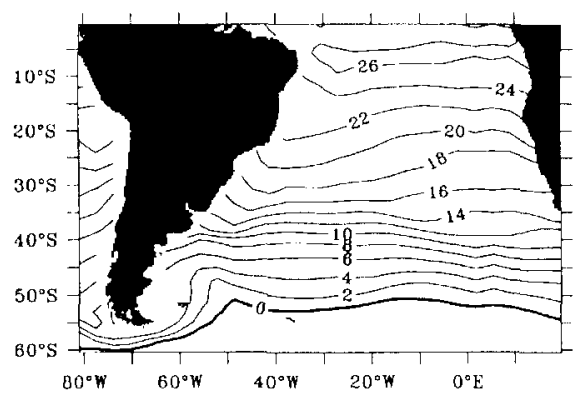

Fig. 2. Climatologia sazonal da TSM para o periodo pré-industrial: (a) verão; (b) outono: (c) inverno; e, (d) primavera. Intervalos de contornos de $2^{\circ} \mathrm{C}$.

A costa sudeste da América do Sul apresenta maiores gradientes de TSM e um deslocamento de águas mais frias próximo à Confluência das Correntes do Brasil e das Malvinas. As águas frias alcançam menores latitudes na costa da América do Sul durante $o$ inverno (Fig. 2c). Essa região é caracterizada por intensos gradientes termohalinos e intensas atividades de mesoescala (Gordon, 1989). O encontro das duas correntes mostra grandes variações sazonais nos parâmetros de superfície marinha, principalmente da TSM (Wainer et al., 2000).

A Figura 2 mostra a climatologia sazonal do período pré-industrial para a região de estudo. Ao longo do ano as isotermas sofrem deslocamentos meridionais, aquecendo as águas superficiais no verão e resfriando-as no inverno.

\section{Pressão Atmosférica ao Nivel do Mar (PNM)}

A Figura 3 apresenta a climatologia anual da PNM e sua respectiva variância para o período préindustrial na região de estudo. O Atlântico Sul é caracterizado por um centro de alta pressão localizado na parte central do oceano, associado a valores superiores a $1020 \mathrm{mbar}$, indicando a presença do anticiclone do Atlântico Sul. Ao sul de $40^{\circ} \mathrm{S}$, as isolinhas adquirem forma zonal e intenso gradiente meridional. Nessa região, os ventos de oeste associados ao anticiclone atravessam o oceano desde a costa sul da América até a África. Sobre o continente, a PNM mostra menores valores.

A PNM apresenta alta variância sobre 0 continente (Fig. 3b), com valores de $20^{\circ} \mathrm{C}^{2}$ na região central da América do Sul. Na região equatorial a variância é menor atingindo apenas $5^{\circ} \mathrm{C}^{2}$, enquanto que nas latitudes mais altas, a variância aumenta alcançando seu máximo de $35^{\circ} \mathrm{C}^{2}$ em torno de $60^{\circ} \mathrm{S}$.

Durante todo o ano, a PNM sofre algumas variações, conforme mostra a Figura 4 da climatologia sazonal do periodo pré-industrial. $O$ centro de alta pressão do Atlântico Sul (Alta Subtropical) é mais intenso no inverno do que no verão, contrariamente aos centros de alta dos outros oceanos. O centro da Alta Subtropical migra sazonalmente (Fig. 4), sendo localizada mais ao sul no verão (em torno de $32^{\circ} \mathrm{S}$ ) e mais ao norte no inverno, em aproximadamente $26^{\circ} \mathrm{S}$. Juntamente com - deslocamento da Alta Subtropical, ocorre a migração da Zona de Convergencia Intertropical (ZCIT), determinando, entre o verão e o outono (mais especificamente entre fevereiro e maio, segundo Quadro et al., 1996) a estação chuvosa na parte norte do nordeste brasileiro (Hastenrath, 1991). 
As diferenças de pressão entre o centro da alta e as costas da América do Sul e da África são maiores no verão, resultado direto das baixas que se desenvolvem sobre cada continente durante essa estação (Satyamurty et al., 1998). Conseqüentemente, os ventos ao longo da costa oeste da
África e as ressurgências associadas são maiores no verão. Como o centro da alta permanece sobre a porção leste do Atlântico Sul, os ventos alísios próximo ao sudoeste africano são geralmente maiores que os ventos próximo à costa brasileira.
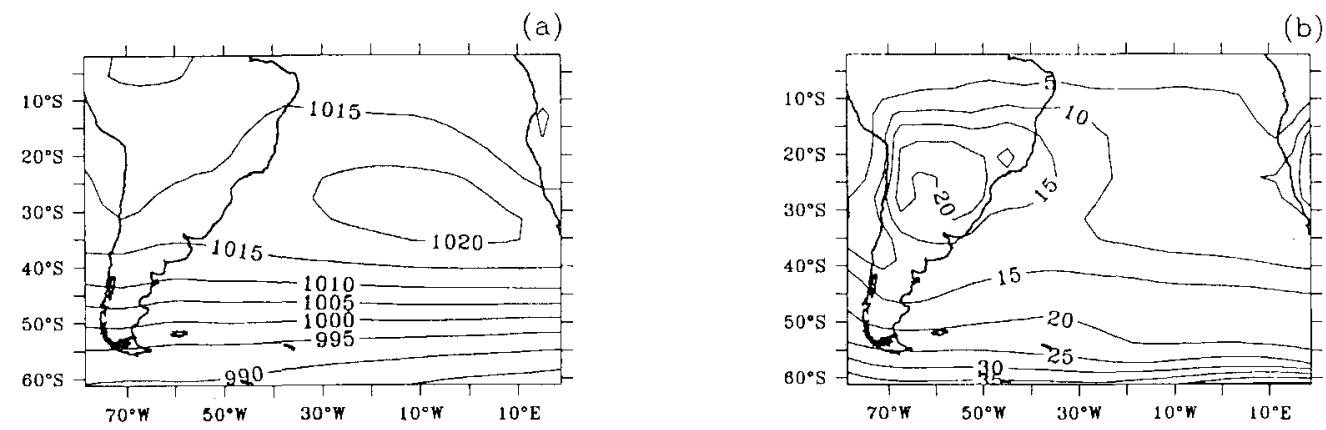

Pig. 3. (a) Climatologia anual da PNM. Intervalos de contornos de 5 mbar. (b) Variância da PNM para o periodo pré-industrial. Intervalos de contomos de 5 mbar ${ }^{2}$.

(a)

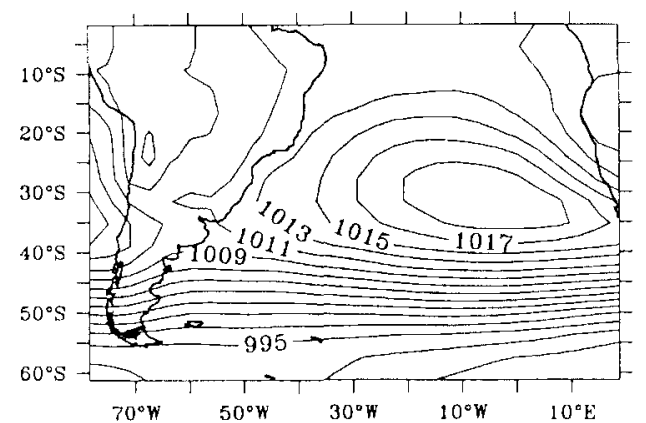

(c)

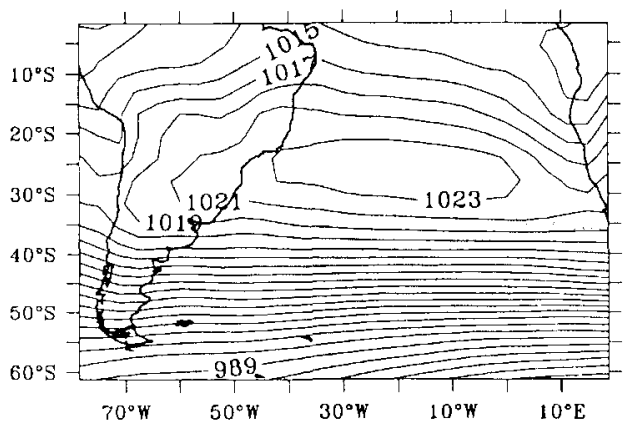

(b)

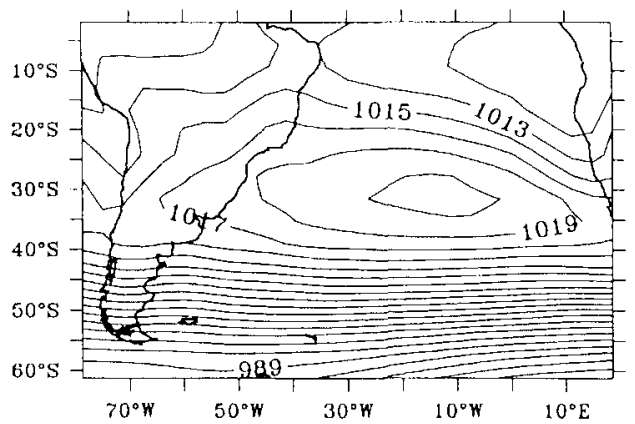

(d)

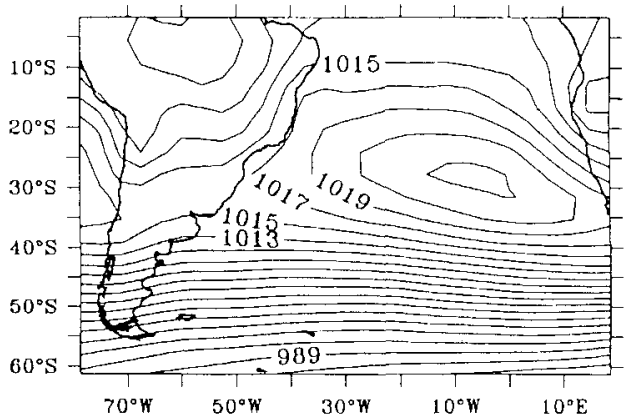

Iig. 4. Climatologia sazonal da PNM para o período pre-industrial: (a) verão: (b) outono: (c) inverno: c. (d) primavera. Intervalos de contornos de 2 mbar 
Função de Corrente do Transporte Barotrópico (TB)

O transporte barotrópico é calculado através da integração da velocidade horizontal u e v desde a elevação da superfície $\eta$ até o fundo $\mathrm{H}$ do oceano, isto é:

$$
T_{x}=\int_{H}^{l} \rho u d z \quad \text { e } \quad T_{y}=\int_{H}^{l} \rho v d z
$$

onde $\rho$ é a densidade da água.

A função de corrente do transporte barotrópico é uma forma de representar os vetores tangentes à direção da integração.

A climatologia anual do TB é apresentada na Figura 5a. Uma vez que a aproximação é barotrópica, os vetores velocidades adquirem a mesma intensidade ao longo da coluna de água. Pode-se verificar valores negativos do TB sobre a região central do Atlântico Sul, em aproximadamente $35^{\circ} \mathrm{S}$, representando o transporte no Giro Subtropical anticiclônico. Ao sul de $40^{\circ} \mathrm{S}$, observa-se valores positivos da função de corrente com alto gradiente em direção ao pólo. Isolinhas paralelas contornam o sul do continente, seguindo para a região da Confluência BrasilMalvinas, fluindo para leste e atravessando o oceano. Esse trajeto é associado ao TB das Correntes das Malvinas, Corrente do Atlântico Sul e Corrente Circumpolar Antártica. Os maiores valores do TB estão associados à Corrente Circumpolar Antártica, entre as latitudes de $50^{\circ} \mathrm{S}$ e $60^{\circ} \mathrm{S}$.

A variância do $\mathrm{TB}$, apresentada na Figura 5 b, revela intensos valores sobre a região sudeste estudada. Em torno de $57^{\circ} \mathrm{S}, 0^{\circ} \mathrm{E}$, esta variância mostra valores superiores a $450 \mathrm{~Sv}^{2}$, indicando alta variabilidade da Corrente Circumpolar Antártica.

A Figura 6 mostra a climatologia sazonal do TB. No inverno (Fig. 6c) o TB ao sul de $40^{\circ} \mathrm{S}$ é mais intenso do que no verão (Fig. 6a). De forma contrária, o transporte no interior do Giro Subtropical é mais intenso no verão, conforme mostra a Figura 6 . Durante a primavera (Fig. 6d) é possivel observar a formação de uma banda de transporte nulo desde a costa da África que se estende até aproximadamente $10^{\circ} \mathrm{W}$, indicando função de corrente negativa, isto é, em sentido anti-horário. Essa pequena célula de circulação anti-ciclônica é intensificada no verão (Fig. 6a) e pode estar associada ao Domo de Angola (Reid, 1989).

$\mathrm{O}$ TB ao sul de $50^{\circ} \mathrm{S}$ nos dois experimentos apresenta, em geral, valores superestimados, devido à maior magnitude da tensão de cisalhamento do vento simulada no modelo acoplado, tendência conhecida do modelo e descrita no trabalho de Danabasoglu (1988).

\section{Diferenças anual e sazonal entre os experimentos pré e pós-industrial}

\section{Temperatura da Superficie do Mar (TSM)}

A Figura 7 apresenta o ciclo anual para a média de toda a região de estudo, das duas simulações. Observa-se que apesar de concordantes em fase, o ciclo climatológico anual do Atlântico Sul revela diferenças significativas entre os períodos. A maior diferença na média da região estudada ocorre principalmente entre os meses de agosto a outubro, ultrapassando $0,9^{\circ} \mathrm{C}$ em setembro.

As diferenças na média anual da TSM entre os dois experimentos são apresentadas na Figura 8, onde os valores positivos indicam intensificação da variável no período pós-industrial em relação ao pré-industrial. $O$ oceano Atlântico Sul mostra diferenças positivas na maior parte da bacia, com maiores valores principalmente ao longo de $50^{\circ} \mathrm{S}$ aproximadamente. O maior aquecimento do período pós em relação ao pré-industrial localiza-se ao sul do continente sul-americano e entre as longitudes de $40^{\circ} \mathrm{W}$ e $10^{\circ} \mathrm{W}$, onde atinge $1,4^{\circ} \mathrm{C}$ em torno de $20^{\circ} \mathrm{W}, 50^{\circ} \mathrm{S}$. Nota-se também regiões onde não ocorre aumento de temperatura: à leste da costa do Brasil e de $60^{\circ} \mathrm{W}$ a $20^{\circ} \mathrm{E}$ ao longo da latitude de $60^{\circ} \mathrm{S}$.
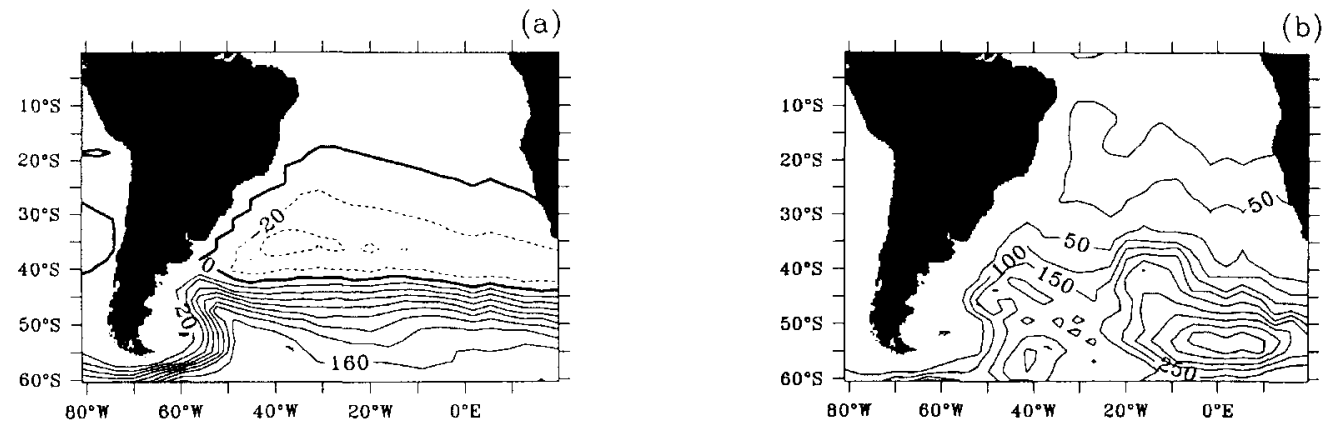

Fig. 5. (a) Climatologia anual do TB. Intervalos de contornos de 20 Sv. (b) Variância do TB para o periodo pre-industrial. Intervalos de contornos de $50 \mathrm{~Sv}^{2}$ 
(a)

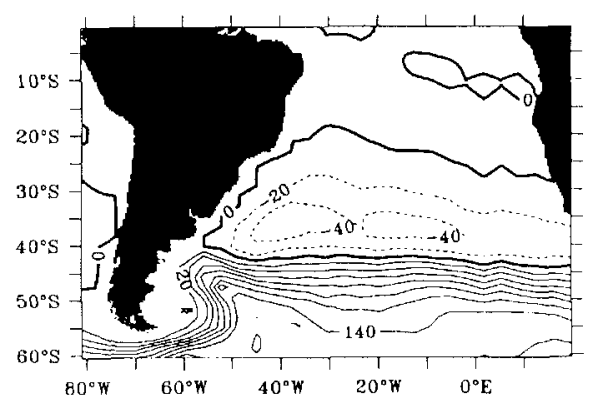

(c)

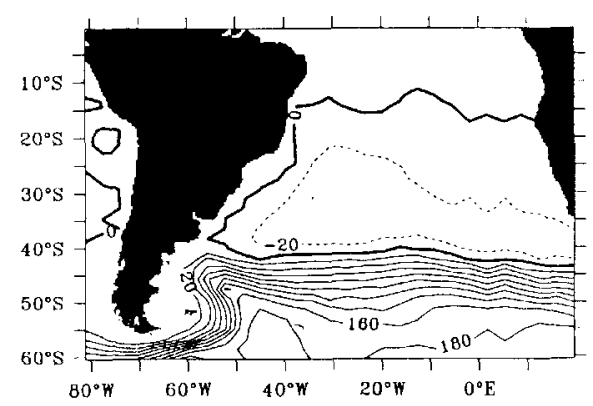

(b)

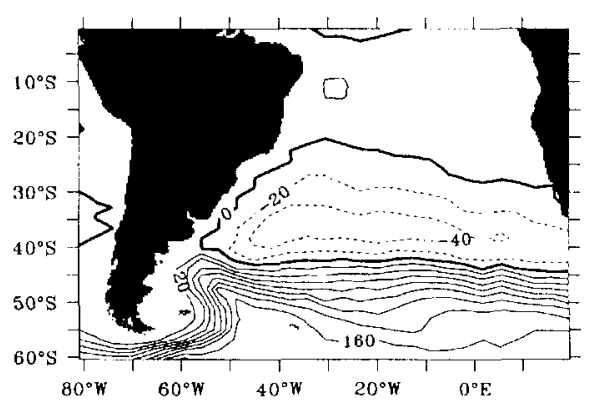

(d)

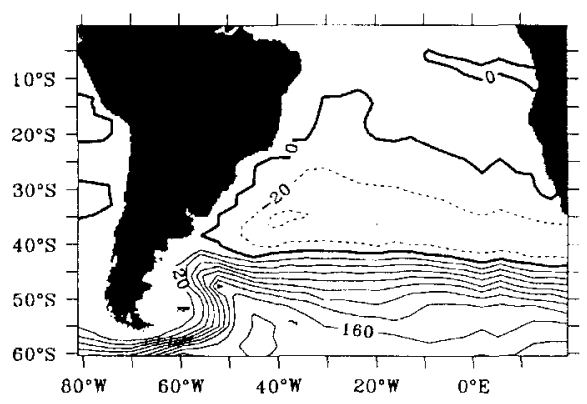

Fig. 6. Climatologia sazonal do T13 para o periodo pré-industrial: (a) verão: (b) outono; (c) inverno; e. (d) primavera. Intervalos de contornos de $20 \mathrm{~Sv}$.

TSM

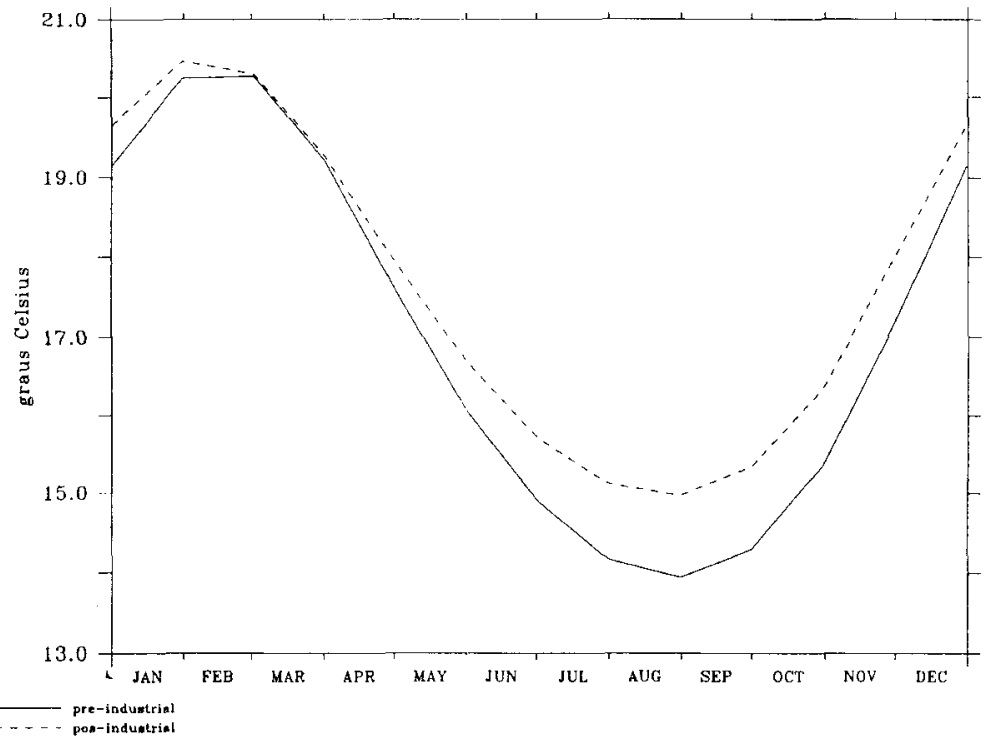

Fig. 7. Ciclo anual para a TSM em ${ }^{\circ} \mathrm{C}$. Linha continua: experimento pré-industrial. Linha tracejada: experimento pós-industrial. 
A Figura 9 mostra as diferenças sazonais da TSM entre os dois períodos simulados. O primeiro semestre (Fig. 9a e 9b) apresenta tanto regiões de aquecimento quanto de resfriamento relativos. No verão (Fig. 9a) existem diferenças positivas em grande parte da bacia, e negativas na porção leste do oceano e ao sul de $60^{\circ} \mathrm{S}$. No outono (Fig. 9b) nota-se bandas de resfriamento relativo ao período pré-industrial (entre $10^{\circ} \mathrm{S}$ e cerca de $35^{\circ} \mathrm{S}$ e ao sul de aproximadamente $55^{\circ} \mathrm{S}$ ), que se estendem zonalmente, e são intercaladas com regiões de aquecimento (ao norte de $10^{\circ} \mathrm{S}$ e entre $35^{\circ} \mathrm{S}$ e aproximadamente $50^{\circ} \mathrm{S}$ ). Nos meses de inverno (Fig. 9c) o Atlântico Sul é dominado por diferenças positivas de temperatura, representando o aquecimento médio da bacia do período pré para o pós-industrial. Um pequeno núcleo de diferenças nulas permanece na porção leste do oceano. Na primavera (Fig. 9d) o aquecimento é intensificado, alcançando as maiores diferenças ao sul do continente americano com valores superiores a $2,5^{\circ} \mathrm{C}$.
O aumento da concentração dos gases estufa intensifica a capacidade de absorção da radiação de onda longa da atmosfera. Com um maior aprisionamento de calor, a atmosfera aumenta sua temperatura e, através da troca de calor entre o oceano e a atmosfera, faz com que ocorra aumento também da TSM. Devido ao alto calor específico, o oceano tem grande poder de armazenar calor e por isso a resposta deste ao aquecimento da atmosfera se dá de forma mais vagarosa. O aumento da TSM, porém, não é distribuído igualmente no espaço: nas latitudes mais altas o aquecimento é maior. No verão, quando a cobertura de gelo é reduzida, o albedo diminui, resultando em maior absorção da radiação de onda curta sobre a superfície. $O$ aquecimento adicional da atmosfera faz com que o oceano absorva mais calor. Esse calor armazenado, porém, retarda o aparecimento do gelo do mar na estação seguinte, reduzindo sua espessura no inverno e produzindo um aquecimento precoce na primavera (Manabe \& Stouffer, 1994)

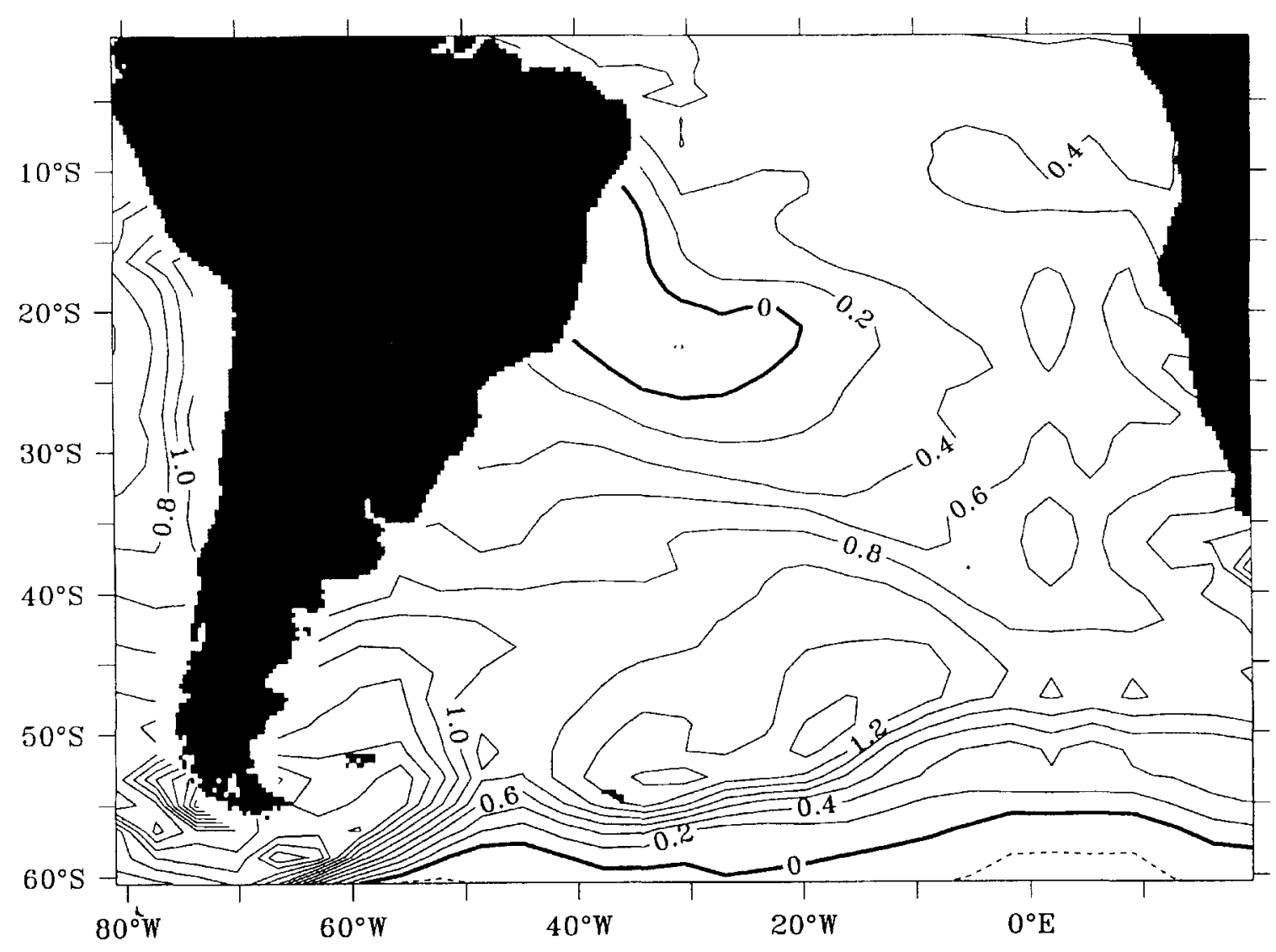

Fig. 8. Diferença entre a climatologia anual da TSM dos dois experimentos. Intervalos de contornos de $0,2^{\circ} \mathrm{C}$. 
(a)

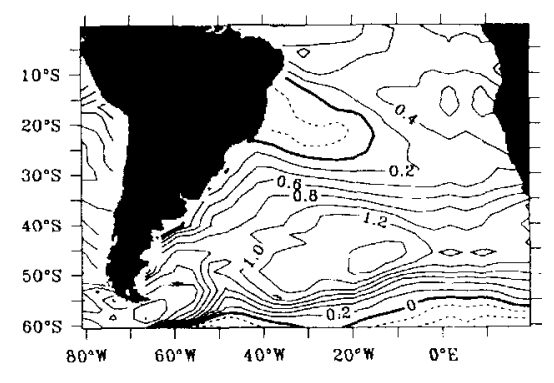

(c)

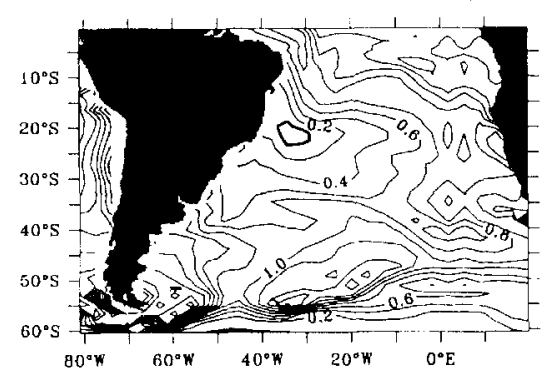

(b)

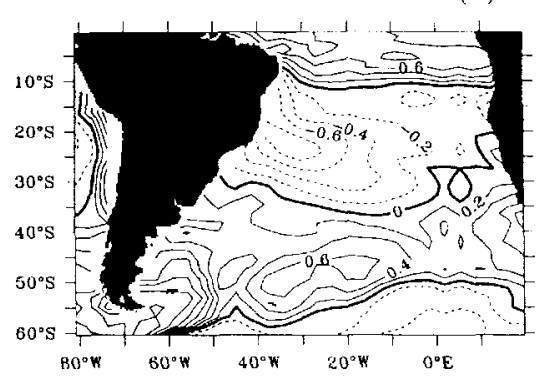

(d)

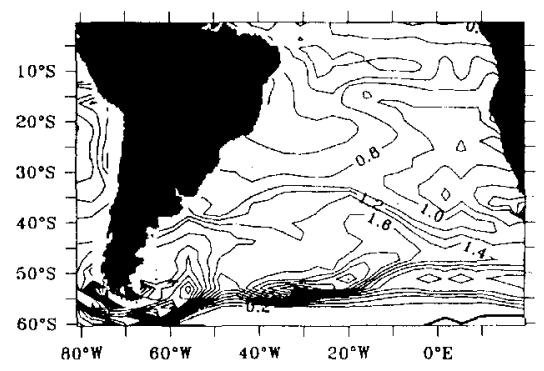

Fig. 9. Diferença entre a climatologia sazonal da TSM dos dois experimentos: (a) verão; (b) outono; (c) inverno e (d) primavera. Intervalos de contornos de $0.2^{\circ} \mathrm{C}$.

\section{Pressão atmosférica ao Nivel do Mar (PNM)}

O ciclo anual da PNM média da região de estudo, apresentado na Figura 10, revela algumas diferenças entre os experimentos, sendo máxima nos meses de verão.

A Figura 11 mostra que na climatologia anual, o oceano Atlântico Sul apresenta diferenças predominantemente positivas entre os dois períodos, sendo maior ao longo de uma faixa transversal que corta o Atlântico desde o nordeste brasileiro até $50^{\circ} \mathrm{S}$. Os contornos positivos indicam intensificação da PNM no período pós-industrial em relação ao préindustrial. Sobre o continente as diferenças são praticamente nulas, com uma pequena região em torno de $32^{\circ} \mathrm{S}, 68^{\circ} \mathrm{W}$, onde a PNM torna-se menor no período pós em relação ao pré-industrial.

$\mathrm{Na}$ análise sazonal é possível observar consideráveis diferenças em todas as estações do ano, principalmente durante o verão (Fig. 12). No primeiro semestre (Figs 12a e 12b), o período pós-industrial mostra maiores valores de PNM em toda a região de estudo. No verão (Fig. 12a) essa diferença é bastante evidente ao sul de $35^{\circ} \mathrm{S}$, onde atinge $2 \mathrm{mbar} \mathrm{em}$ aproximadamente $30^{\circ} \mathrm{W}, 45^{\circ} \mathrm{S}$. No outono (Fig. 12b) o período pós-industrial mostra valores de pressão superiores a $1,8 \mathrm{mbar}$ em torno de $35^{\circ} \mathrm{W}, 25^{\circ} \mathrm{S}$.
Durante os meses de inverno (Fig. 12c) o período préindustrial revela maiores valores de pressão na maior parte da região de estudo, com diferenças de 1,2 mbar em torno de $55^{\circ} \mathrm{S}, 30^{\circ} \mathrm{W}$. Ainda nos meses de inverno (Fig. 12c) o sul do continente da América do Sul (em até aproximadamente $40^{\circ} \mathrm{S}$ ), e uma banda que se alonga pelo oceano na direção nordeste desde o sul do continente africano mostram diferenças positivas indicando intensificação da PNM no período pósindustrial. $\mathrm{Na}$ primavera (Fig. 12d) as diferenças são menores com diferenças positivas de $0,8 \mathrm{mbar}$ ao longo de $45^{\circ} \mathrm{S}$ entre as longitudes de $20^{\circ} \mathrm{W}$ e $5^{\circ} \mathrm{E}$, e negativas sobre o continente, mais acentuada na direção sul. Durante todo o ano as menores diferenças entre os dois experimentos são encontradas na região equatorial.

\section{Função de corrente do Transporte Barotrópico (TB)}

O ciclo anual da média da região de estudo, apresentado na Figura 13, revela um aumento significativo do TB de um período para o outro. Apesar dos dois experimentos manterem a fase, a média anual é maior para o período pós-industrial. A intensificação do TB no período pós-industrial para média do Atlântico Sul chega a 2,5Sv nos meses de março e julho. 


\section{PNM}

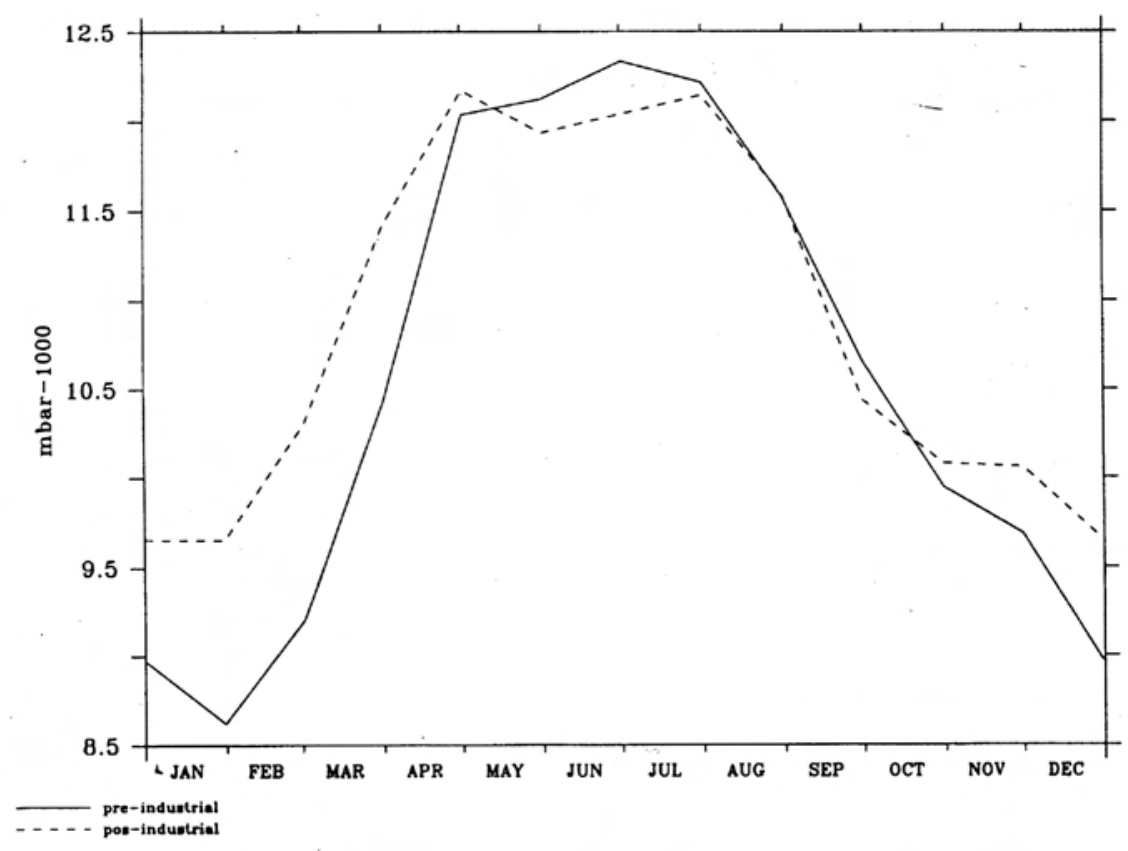

Fig. 10. Ciclo anual da PNM. Linha contínua: experimento pré-industrial. Linha tracejada: experimento pós-industrial. Unidades de mbar-1000.

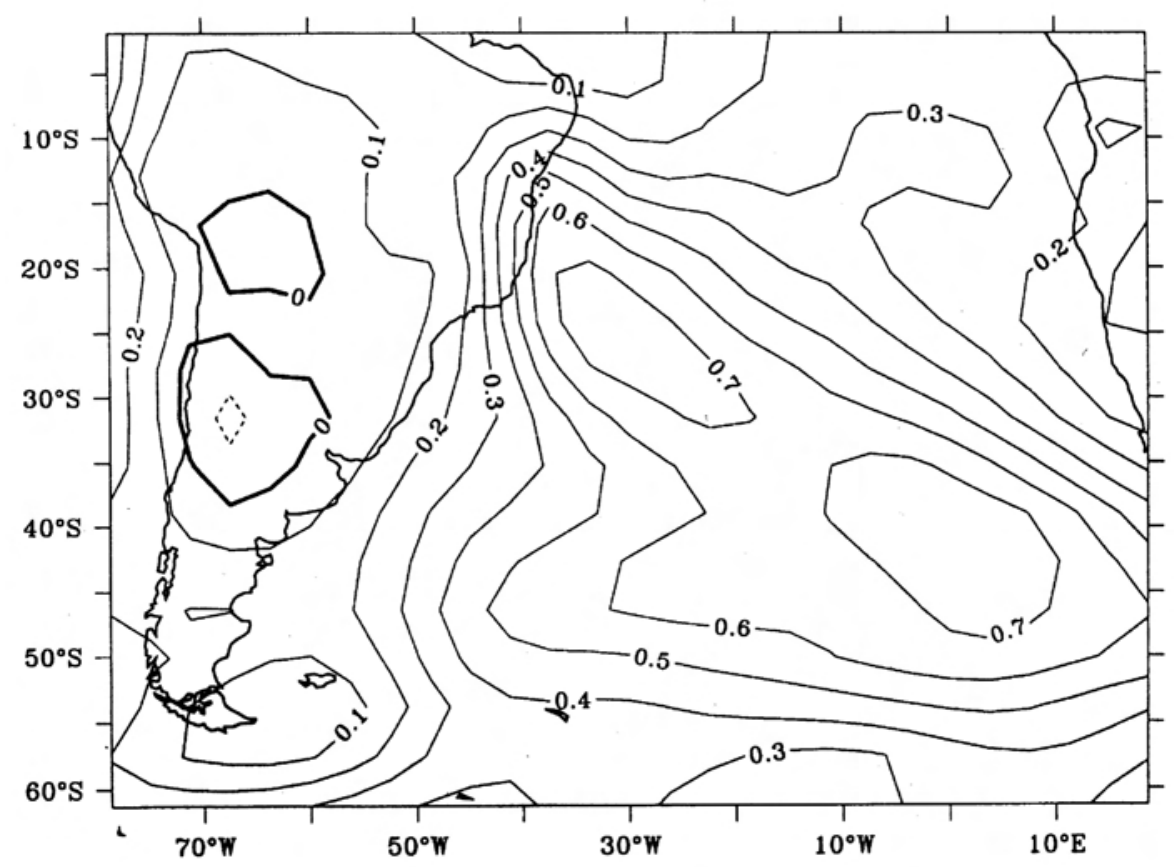

Fig. 11. Diferença entre a climatologia total da PNM dos dois experimentos. Intervalos de contornos de 0,1 mbar. 
(a)

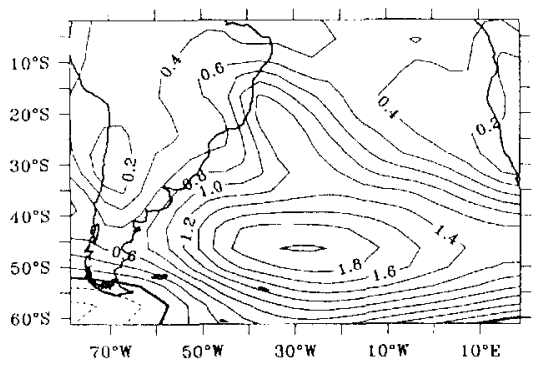

(c)

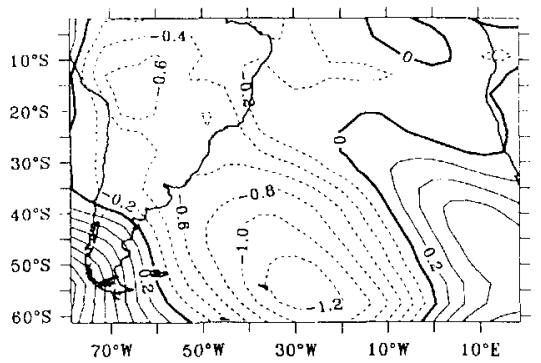

(b)

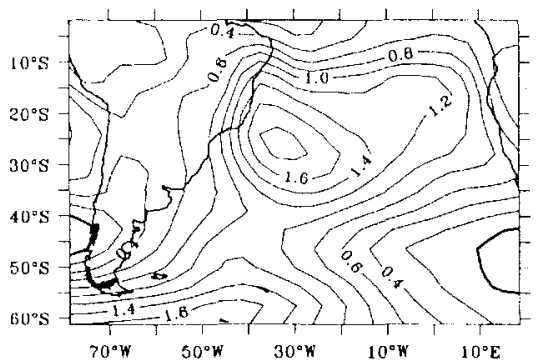

(d)

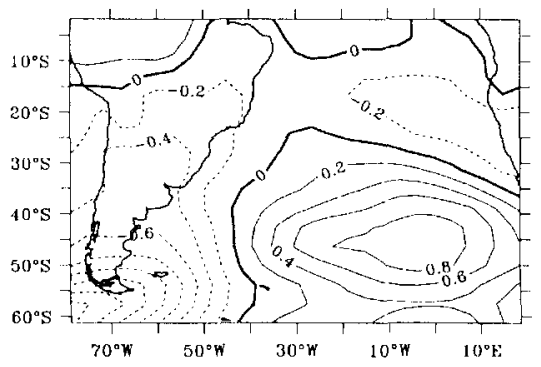

Fig. 12. Diferença entre a climatologia sazonal da PNM dos dois experimentos: (a) verão: (b) outono: (c) inverno e (d) primavera. Intervalos de contomos de 0.2 mbar.

\section{Transporte Barotropico}

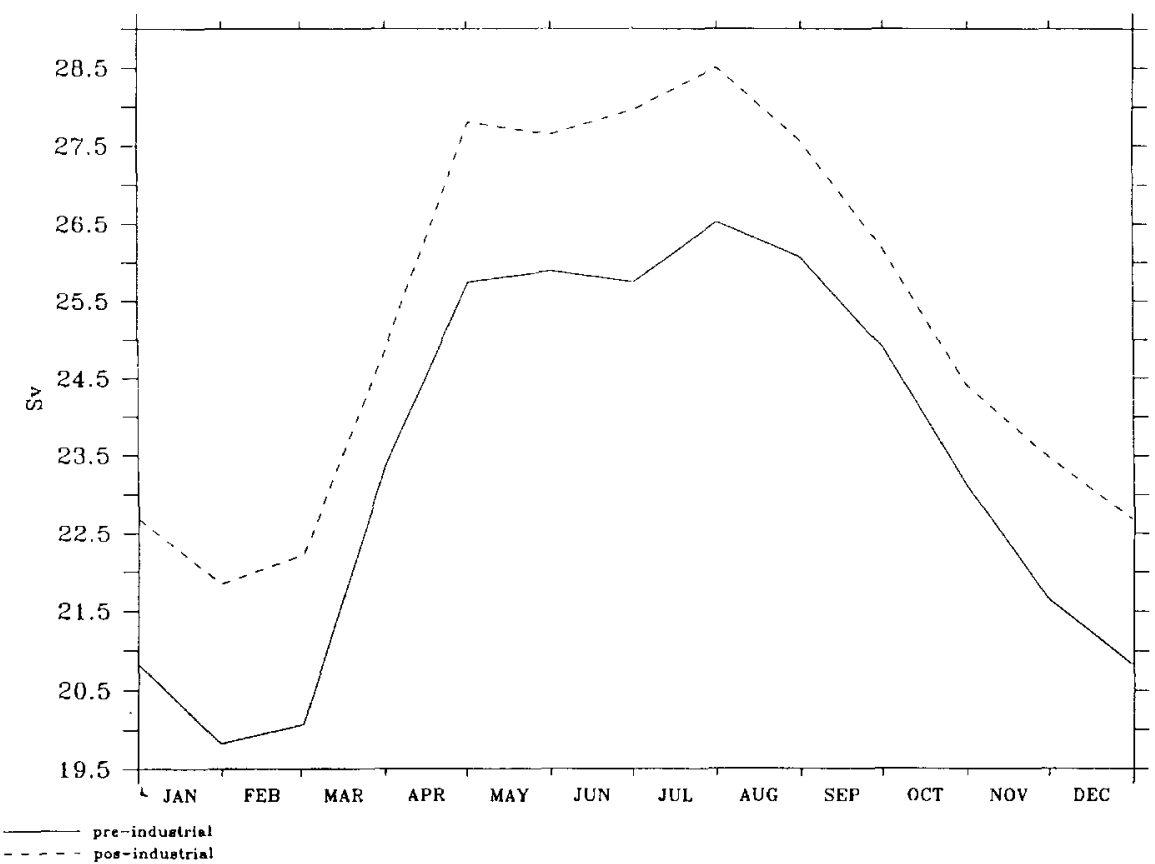

Fig. 13. Ciclo anual do TB em Sv. Linha contínua: experimento pré-industrial. Linha tracejada: experimento pós-industrial. 
A Figura 14 mostra as diferenças espaciais entre a climatologia anual dos dois experimentos. De um modo geral pode-se verificar a intensificação do TB em toda a região de estudo. O experimento pósindustrial apresenta valores consideravelmente maiores ao sul de $45^{\circ} \mathrm{S}$, principalmente ao longo da latitude de $55^{\circ} \mathrm{S}$, entre as longitudes de $10^{\circ} \mathrm{W}$ e $10^{\circ} \mathrm{E}$, onde a diferença atinge 20Sv. O Giro Subtropical também sofre uma leve intensificação em seu interior, ultrapassando $4 \mathrm{~Sv}$.

As diferenças entre as climatologias sazonais dos dois experimentos é apresentada na Figura 15. As maiores discrepâncias ao sul de $45^{\circ} \mathrm{S}$ aparecem no outono (Fig. 15b), onde a diferença entre os transportes barotrópicos chega a $25 \mathrm{~Sv}$ em torno de $55^{\circ} \mathrm{S}, 0^{\circ} \mathrm{E}$. No Giro Subtropical as grandes diferenças ocorrem na primavera (Fig. 15d), quando a intensificação da parte central do Giro Subtropical alcança $8 \mathrm{~Sv}$.

\section{Discussões}

Os resultados desse trabalho mostram que maiores diferenças entre os dois períodos estão localizadas nas latitudes mais altas. Com o intuito de verificar a região de maior impacto devido ao aumento na concentração dos gases estufa, a tabela a seguir resume as diferenças da média anual de cada variável em toda a bacia do Atlântico Sul, e nas regiões entre o equador até $40^{\circ} \mathrm{S}$ e ao sul dessa latitude.

Verifica-se que a média anual em toda a região de estudo do experimento pós-industrial apresenta maiores valores nas variáveis estudadas. A intensificação no período pós-industrial entre o equador e $40^{\circ} \mathrm{S}$ ocorre com menor intensidade em todas as variáveis, porém a diferença de $0,5^{\circ} \mathrm{C}$ na TSM já é considerada bastante significativa em relação ao ciclo anual. Mas a grande diferença espacial entre os dois experimentos ocorre ao sul de $40^{\circ} \mathrm{S}$. A TSM sofreu um aumento médio de $0,9^{\circ} \mathrm{C}$ nessa região, enquanto que a PNM apresentou intensificação média no período pós-industrial de $0,4^{\circ} \mathrm{C}$ para a mesma área. O TB é a variável que mostrou maior discrepância entre os dois experimentos, revelando diferença média de $6,4 \mathrm{~Sv}$ ao sul de $40^{\circ} \mathrm{S}$.

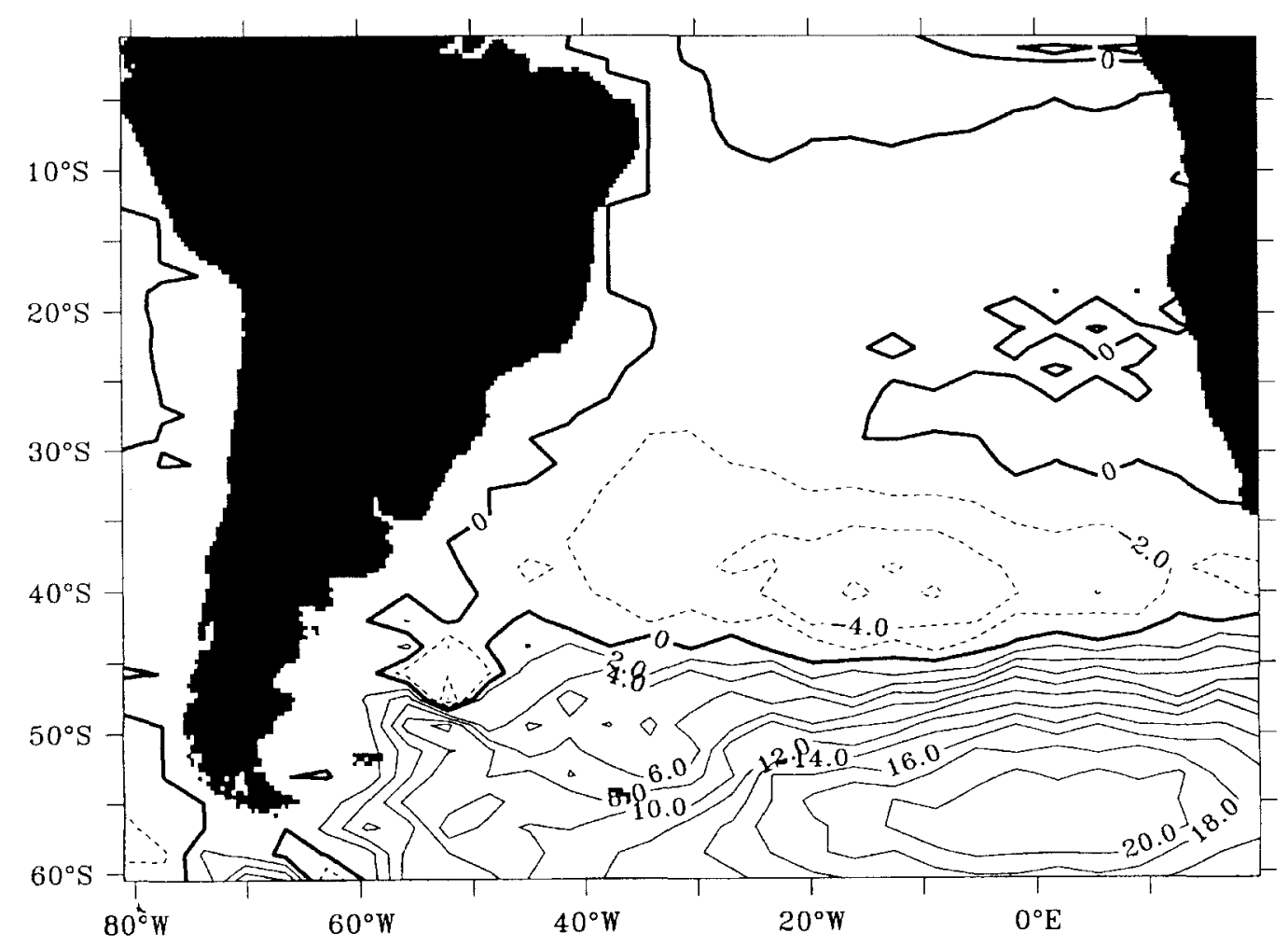

Fig. 14. Diferença entre a climatologia anual do TB dos dois experimentos. Intervalos de contornos de $2 \mathrm{~Sv}$. 
(a)

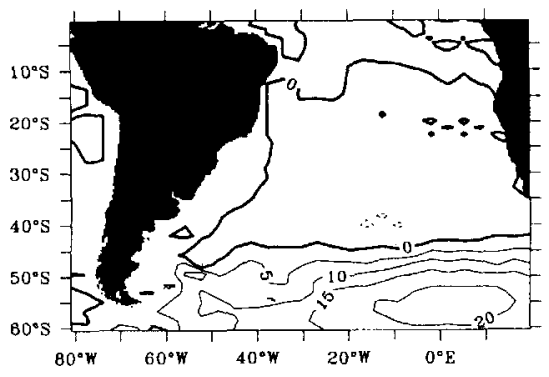

(c)

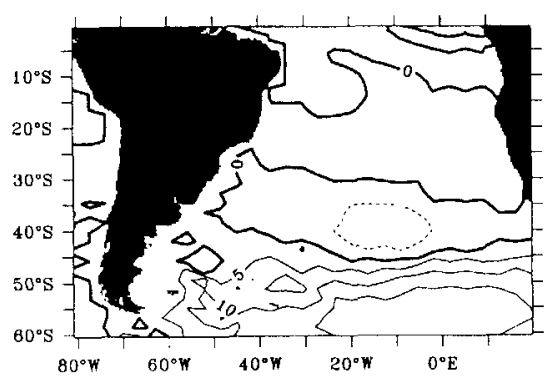

(b)

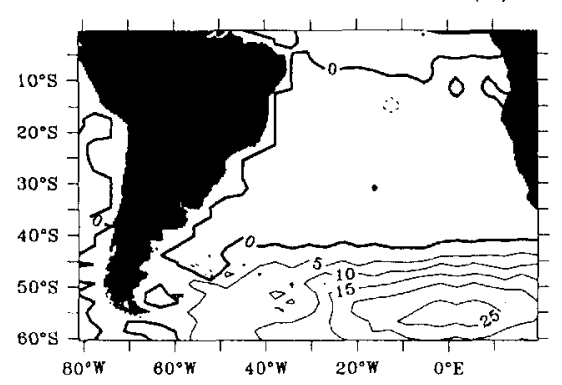

(d)

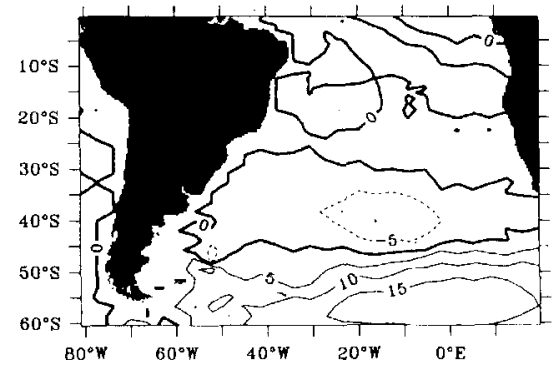

Fig. 15. Diferença entre a climatologia sazonal do TB dos dois experimentos: (a) verão; (b) outono; (c) inverno e (d) primavera. Intervalos de contornos de 5 Sv.

\section{Conclusões}

Neste trabalho foi realizado um estudo sobre as mudanças no comportamento sazonal e anual da temperatura da superfície do mar (TSM), pressão atmosférica ao nível do mar (PNM) e transporte barotrópico (TB) devido ao aumento na concentração dos gases estufa. Foram utilizadas duas simulações do modelo acoplado NCAR CCSM sob as condições atmosféricas do período pré-industrial e pósindustrial. Os resultados mostram, de uma maneira geral, intensificação das variáveis estudadas para o período pós-industrial.

O ciclo anual da média da região de estudo da TSM mostrou um aquecimento em relação ao período pré-industrial entre os meses de agosto a outubro, sendo a maior diferença de TSM em setembro. As maiores mudanças na média anual da TSM ocorreram entre as latitudes de $40^{\circ} \mathrm{S}$ e $55^{\circ} \mathrm{S}$ e durante a primavera. Um resfriamento considerável também pode ser observado durante o outono na porção centro-norte da bacia, com diferenças de até $0,8^{\circ} \mathrm{C}$.

A PNM revelou maiores diferenças durante os meses de verão, quando a pressão atmosférica é menor, com intensificação no período pós-industrial, enquanto que durante o inverno ocorreu diminuição da PNM em relação ao período pré-industrial em grande parte da região de estudo.

$O$ TB foi a variável que mais sofreu influência do aumento dos gases estufa simulado. A média da região apresenta um ciclo anual com diferenças de $2,5 \mathrm{~Sv}$ ao longo do ano entre os dois períodos, com aumento no período pós-industrial. Esse aumento deve-se basicamente à intensificação do TB durante todas as estações do ano sobre a Corrente Circumpolar Antártica. O Giro Subtropical também sofreu aumento de TB, de menor intensidade, durante o período pós-industrial, principalmente durante o segundo semestre.

Com este estudo foi possível observar algumas alterações no comportamento das variáveis aqui analisadas, mas os mecanismos físicos que expliquem as relações de causa e efeito ainda são objeto de estudo, devido à complexidade dos processos oceânicos e atmosféricos.

\section{Agradecimentos}

As autoras contaram com o apoio de recursos dos seguintes projetos para a realização 
desse trabalho: $\mathrm{CNPq}$ 300223/93-5, CNPq 30040/946, FAPESP 00/2958-7 e FAPESP 02/01211-0. I. W. agradece também a National Science Foundation, através do programa SGER. Agradecemos também o projeto: Variabilidade ambiental na Antártica setentrional e no oceano circum-polar CNPq $550363 / 02-5$.

\section{Referências bibliográficas}

Angell, J. K. 1986. Annual and seasonal global temperature changes in the troposphere and low stratosphere, 1960-1985. Mon. Weath. Rev., 114(10):1922-1930.

Bonan, G. B. 1996. A land surface model (LSM version 1.0) for ccological, hydrological, and atmospheric studies: technical description and user's guide. NCAR Technical Note NCAR/TN417, NCAR, Boulder, CO. 150 p.

Boville, B. \& Gent, P. R. 1998. The NCAR Climate System Model, version one. J. Clim., 11(6):11151130 .

Bradley, R. S.; Diaz, H. F.; Eischeid, J. K.; Jones, P. D.; Kelly, P. M. \& Goodess, C. M. 1987. Precipitation fluctuations over Northern Hemisphere land areas since the mid-nineteenth century. Science, 237(4811):171-175.

Cane, M. A.; Clement, A. C.; Kaplan, A.; Kushnir, Y.; Pozdnyakov, D.; Seager, R.; Zebiak, S. E. \& Murtuguddenatuer, R. 1997. Twentieth-century sea surface temperature trends. Science, 275(5302):957-960

Crowley, T. J. 2000. Causes of climate change over the past 1000 years. Science, 289(5477):270-277.

Danabasoglu., G. 1988. On the wind-driven circulation of the uncoupled and coupled NCAR Climate System Ocean Model. J. Clim., $11(6): 1442-1454$.

da Silva, A.; Young, A. C. \& Levitus, S. 1994. Atlas of Surface Marine Data 1994, v.1: Algorithms and Procedures. NOAA Atlas NESDIS 6. Washington, DC.

Fluckiger, J.; Dallenbach, A.; Blunier, T.; Stauffer, B.; Stocker, J. T. F.; Raynaud, D. \& Barnola, J.-M. 1999. Variations in atmospheric $\mathrm{N}_{2} \mathrm{O}$ concentration during abrupt climatic changes Science, 285(5425):227-230.
Gates, D. M. 1993. Climate change and its biological consequences. Massachusetts, Sinauer Associates. $280 \mathrm{p}$

Gent, P. R.; Bryan, F. O.; Danabasoglu, G.; Doney, S. C.; Holland, W. R.; Large, W. G. \& McWilliams, J. C. 1998. The NCAR Climate System Model global ocean component. J. Climate, 11(6):12871306.

Gordon, A. L. 1989. Brazil-Malvinas confluence. Deep Sea Res., 36(3A):359-384.

Hastenrath, S. 1991. Climate dynamics of the tropics. Dordrecht, Kluwer Academic Publishers. 488p

Houghton, J. T.; Meira Filho, L. G.; Callender, B. A.; Harris, N.; Kattenberg, A. \& Maskell, K. 1995 Climate Change 1995: the science of climate change. Cambridge, Cambridge University Press. $2 \mathrm{v}$.

Houghton, J. T.; Callander, B. A. \& Varney, S. K. 1992. Climate change 1992: the supplementary report to the $I P C C$ scientific assessment Cambridge, Cambridge University Press. 200 p.

Houghton, R. A. \& Woodwell, G. M. 1989. Global climatic change. Scientific American, 260(4):3644.

Ice Core Working Group. 1998. Ice core contributions to global change research': past successes and future directions. University of New Hampshire, The National Ice Core Laboratory.

Indermuhle, A.; Stocker, T. F.; Joos, F.; Fischer, H.; Smith, H. J.; Wahlen, M.; Deck, B.; Mastroianni, D.; Tschumi, J.; Blunier, T.; Meyer, R. \& Stauffer, B. 1999. Holocene carbon-cycle dynamics based on $\mathrm{CO}_{2}$ trapped in ice at Taylor Dome, Antartica. Nature, 398(6723):121-126.

Karl, T. R.; Kukla, G.; Razuvayev, V. N.; Changery, M. J.; Quayle, R. G.; Heim Jr., R. R.; Easterling, D. R. \& Fu, C. B.1991. Global warming: evidence for assymmetric diurnal temperature change. Geophys. Res. Letts, 18(2):2253-2256.

Levitus, S.; Antonov, J. I.; Boyer, T. P. \& Stephens, C. 2000. Warming of the world ocean. Science, 287(5461):2225-2229.

Manabe, S. \& Stouffer, R. J. 1994. Multiple-century response of a coupled ocean-atmosphere model to an increase of atmospheric carbon-dioxide. J. Clim., 7(1):5-23. 
Manabe, S.: Wetherald, R. T. \& Stouffer, R. J. 1981. Summer dryness due to an increase of atmospheric $\mathrm{CO}_{2}$ concentration. Clim. Change, 3(4):347-385.

Matear, R. J. \& Hirst, A. C. 1999. Climate change feedback on the future oceanic $\mathrm{CO} 2$ uptake. Tellus B, 51(3):722-733.

McCabe, G. J.; Clark, M. P. \& Serreze, M. C. 2001. Trends in Northern Hemisphere surface cyclone frequency and intensity. J. Climate, 14(12):27632768.

Mitchell, J. F. B. 1989. The greenhouse effect and climate change. Rev. Geophys., 27(1):115-139.

Quadro, M. F. L.; Machado, L. H. R.; Calbete, S. Batista, N. N. M. \& Oliveira, G. S. de. 1996. Climatologia de precipitação e temperatura. Climanálise, edição especial comemorativa de 10 anos.

Reid, J. L. 1989. On the total geostrophic circulation of the South Atlantic Ocean: Flow patterns, tracers and transports. Prog. Oceanogr., 23:149244.

Reynolds, R. W. \& Smith, T. M. 1994. A high resolution global sea surface temperature climatology. J. Climate, 7(6):929-948.

Robin, G. de Q. 1986. Changing the sea level: projecting the rise in sea level caused by warming of the atmosphere. In: Bolin, B.; Doos, B. R.; Jager, J. \& Warnick, R. A. eds. The Greenhause effect climate change and ecosystems scope. New York, Scope, 29:323-359.
Satyamurty, P.; Nobre, C. A. \& Dias, P. L. S. 1998. Meteorology of the Southern Hemisphere: South America. Met. Monogr., 27(49):119-139.

Semtner Jr., A. J. 1976. A model for the thermodynamic growth of sea ice in numerical investigations of climate. J. Phys. Oceanogr., $6(3): 379-389$

Skinner, B. J. \& Porter, S. C. 1995. The blue planet: an introduction to earth system science. New York, John Wiley e Sons. 493p.

Solomon, A. M.; Trabalka, J. R.; Reichle, D. E. \& Voorhees, L. D. 1985. The global cycle of carbon. In: Trabalka, J. R. ed. Atmospheric carbon dioxide and the global carbon cycle. Washington, DC., Dept. of Energy. p.3-24.

Wainer, I.; Gent, P. \& Goni, G. 2000. Annual cycle of the Brazil-Malvinas confluence region in the National Center for Atmospheric Research Climate System Model. J. geophys. Res., 105(C11):26167-26177.

Wigley, T. M. L. \& Raper, S. C. B. 1987. Thermal expansion of sea water associated with global warming. Nature, 330(6144):127-131.

(Mamuscrito recebido 08 abril 2002; revisado 02 julho 2002; aceito 11 novembro 2002) 